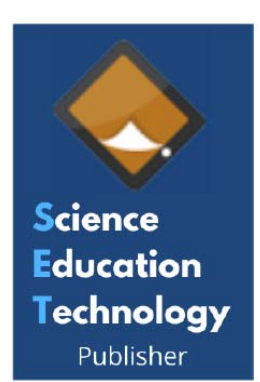

\title{
Semi-Refined Carrageenan Attenuates Lipopolysaccharide-Induced Reactive Oxygen Species Production in Peripheral Blood Mononuclear Cells and Cell Membrane Alterations in Leukocytes
}

\begin{abstract}
Yevgen Posokhov ${ }^{1,2}$, Anatolii Onishchenko ${ }^{2,3}$, Tetyana Chumachenko ${ }^{4}$, Nataliia Makieieva ${ }^{5}$, Yuliia Kalashnyk-Vakulenko ${ }^{6}$, Hanna Polikarpova ${ }^{3}$, Viktoriia Novikova ${ }^{7}$, Volodymyr Prokopyuk ${ }^{2,8}$, Oksana Nakonechna $^{3}$, Dmytro Chumachenko ${ }^{9}$, Viktoriya Tkachenko ${ }^{10}$, levgen Meniailov ${ }^{9}$, Maryna Tkachenko ${ }^{11}$, and Anton Tkachenko ${ }^{2,3, *}$

${ }^{1}$ Department of Organic Chemistry, Biochemistry and Microbiology, The National Technical University "Kharkiv Polytechnic Institute", Kharkiv, Ukraine; ${ }^{2}$ Research Institute of Experimental and Clinical Medicine, Kharkiv National Medical University, Kharkiv, Ukraine; ${ }^{3}$ Department of Biochemistry, Kharkiv National Medical University, Kharkiv, Ukraine; ${ }^{4}$ Department of Epidemiology, Kharkiv National Medical University, Kharkiv, Ukraine; ${ }^{5}$ Department of Pediatrics No 2, Kharkiv National Medical University, Kharkiv, Ukraine; ${ }^{6}$ Department of Otorhinolaryngology, Kharkiv National Medical University, Kharkiv, Ukraine; ' Department of Chemistry, Biochemistry, Microbiology and Food Hygiene, State Biotechnological University, Kharkiv, Ukraine; ${ }^{8}$ Department of Cryobiology of the Reproduction System, Institute for Problems of Cryobiology and Cryomedicine of the National Academy of Sciences of Ukraine, Kharkiv, Ukraine; ${ }^{9}$ Department of Mathematical Modelling and Artificial Intelligence, National Aerospace University "Kharkiv Aviation Institute", Kharkiv, Ukraine; ${ }^{10}$ D.P. Grynyov Department of Microbiology, Virology and Immunology, Kharkiv National Medical University, Kharkiv, Ukraine; ${ }^{11}$ L.T. Malaya Department of Internal Medicine No. 2, Clinical Immunology and Allergology, Kharkiv National Medical University, Kharkiv, Ukraine
\end{abstract}

\section{Article Info:}

Keywords:

Food additive,

E407a,

2',7'-dichlorodihydrofluorescein

diacetate,

fluorescent probes.

Timeline:

Received: October 25, 2021

Accepted: December 20, 2021

Published: December 25, 2021

Citation: Tkachenko A. Semi-Refined Carrageenan Attenuates Lipopolysaccharide-Induced Reactive Oxygen Species Production in Peripheral Blood Mononuclear Cells and Cell Membrane Alterations in Leukocytes. J Pharm Nutr Sci 2021;

11(1): 175-183.

DOI: https://doi.org/10.29169/1927-5951.2021.11.20
Abstract:

Aim: To assess the effects of semi-refined carrageenan (E407a) on lipopolysaccharide (LPS)induced reactive oxygen species (ROS) generation in peripheral blood mononuclear cells (PBMCs) and LPS-mediated cell membrane alterations in leukocytes.

Methods: Blood samples collected from 8 intact rats were incubated with E407a $(10 \mathrm{mg} / \mathrm{ml})$, E407a $(50 \mathrm{mg} / \mathrm{ml})$, LPS $(1 \mu \mathrm{g} / \mathrm{ml})$, E407a $(10 \mathrm{mg} / \mathrm{ml})+$ LPS $(1 \mu \mathrm{g} / \mathrm{ml})$, E407a $(50 \mathrm{mg} / \mathrm{ml})+$ LPS $(1$ $\mu \mathrm{g} / \mathrm{ml}$ ) and without those compounds (controls) for $2 \mathrm{~h}$ in RPMI 1640 medium enriched with $5 \%$ fetal bovine serum. ROS generation in PBMCs obtained from the incubated samples was estimated by flow cytometry using 2',7'-dichlorodihydrofluorescein diacetate (H2DCFDA) staining. The impact of E407a, LPS and their mixture on leukocyte cell membranes was evaluated spectrofluorimetrically using the fluorescent probe 2-(2'-hydroxy-phenyl)-5-phenyl-1,3-oxazole.

Results: Expectedly, incubation with LPS induced ROS generation in PBMCs and decreased the lipid order of cell membranes in leukocytes. E407a alone was found to alter neither ROS production in PBMCs, nor membrane lipid order in leukocytes. Semi-refined carrageenan partially reduced LPS-mediated ROS overproduction in PBMCs and cell membrane alterations in leukocytes.

Conclusion: E407a attenuates LPS-induced alterations of redox homeostasis in rat PBMCs and LPS-mediated modifications of cell membrane lipid order in leukocytes.

*Corresponding Author

Tel: +38-050-109-45-54

E-mail: as.tkachenko@knmu.edu.ua

(c) 2021 Posokhov et al.; Licensee SET Publisher.

This is an open access article licensed under the terms of the Creative Commons Attribution Non-Commercial License (http://creativecommons.org/licenses/by-nc/3.0/) which permits unrestricted, non-commercial use, distribution and reproduction in any medium, provided the work is properly cited. 


\section{INTRODUCTION}

Natural additives have been gaining popularity for decades due to the awareness about their benefits both among industrial companies and consumers [1]. However, even legally sanctioned food additives originating from naturally occurring sources don't meet high safety standards. Based on these premises, the major European regulatory body the European Food Safety Authority (EFSA) has been carrying out the reevaluation of currently recognized as safe food additives since 2012. Among multiple food additives whose safety for consumers is controversial, carrageenans (registered as E407 and E407a) are of great concern [2]. Carrageenans, which are also referred to as Irish moss, are highly sulfated polyanionic marine polysaccharides with no nutritional value. These polymers are made up of alternating 3-Osubstituted $\beta$-D-galactopyranosyl rings and 4-Osubstituted $\alpha$-D-galactopyranosyl monomers [3]. It is important to note that only high-molecular-weight carrageenans (200-800 kDa) are officially permitted to be used in the food industry as thickeners, gelling agents, emulsifiers and texture improvers (E407 food-grade carrageenan or E407a - semi-refined carrageenan). At the same time, there is compelling evidence that their low-molecular-weight counterparts called degraded carrageenans and poligeenans are toxic and, thus, their use in foodstuffs is officially prohibited [4].

Experimental data indicate that carrageenans induce intestinal inflammation despite their poor or no absorption in the gut $[5,6]$. It should be mentioned that several mechanisms have been suggested to be implicated in the carrageenan-induced intestinal inflammation. In particular, carrageenans have been shown to upregulate interleukin-8 in colonic epithelial cells through the pro-inflammatory bcl10 (B-cell lymphoma/leukemia 10) / NF-kB (nuclear factor kappalight-chain-enhancer of activated $B$ cells) pathway [710]. In addition to the NF-KB-mediated synthesis of proinflammatory cytokines, it has been proven that carrageenans can promote upregulation of interleukin$1 \beta$ via the NLRP3 (NLR family pyrin domain containing 3) inflammasome pathway in macrophages [11]. Furthermore, several studies have suggested the involvement of toll-like receptors (TLRs) in the carrageenan-triggered inflammation $[12,13]$. TLRs are crucial for the innate immune response providing the recognition of pathogen-associated molecular patterns (PAMPs). This TLR+PAMP receptor-ligand binding triggers intracellular signal transduction culminating in the upregulation of pro-inflammatory factors [14]. According to data available, dietary carrageenans can alter the cellular redox homeostasis both upon direct exposure and after their ingestion by experimental animals $[15,16]$.

Accumulating evidence on food-grade carrageenan toxicity $[5,6,10,17-21]$ has established a basis for setting up a programme by the EFSA for the risk assessment of carrageenan consumption. In 2018, the EFSA released a call for technical and toxicological data on carrageenan (E 407) for uses in foods for all population groups including infants below 16 weeks of age (EFSA-Q-number: EFSA-Q-2018-00771).

In contrast to the studies outlined above, some researchers have claimed that carrageenans exert no cytotoxic effects towards different types of cells [22-25]. In particular, a study performed on human intestinal and hepatic cell lines revealed that food-grade carrageenans neither upregulated pro-inflammatory cytokines via the nuclear factor kappa-light-chainenhancer of activated B cells (NF-kB) pathway, nor affected the intracellular redox homeostasis [24]. Semirefined carrageenan has been found to be incapable of triggering apoptosis in leukocytes, but slightly upregulated anti-apoptotic bcl-2 protein in lymphocytes [26]. Moreover, it has been experimentally shown that carrageenans don't stimulate TLR4 signaling [27].

Such inconsistency in experimental data may be explained by either confusion in carrageenan types used in the studies [23], since this group of marine carbohydrates is extremely diverse and heterogeneous, or the fact that cell culture studies exclude the complex cell-cell interactions in the body and the impact of gut microbiota, which can modify the ingested carrageenans. Several studies have suggested that there are links between carrageenan consumption and bacterial intestinal inflammation [28, 29]. However, the mechanisms by which carrageenans may aggravate bacteria-mediated gut inflammation are still poorly understood and required to be scrutinized.

The study was intended for assessing the ability of E407a to aggravate LPS-induced alteration of redox homeostasis and cell membrane structural features in leukocytes.

\section{MATERIALS AND METHODS}

\section{Blood Collection and Preparation of Samples}

A total of 8 adult 5-month-old female WAG rats were selected in the study. Sterile vacutainer test tubes 
(IMPROVACUTER Evacuated EDTA $\mathrm{K}_{2}$ Spray Dried PET Tubes, Guangzhou, China) containing dipotassium ethylenediaminetetraacetate (K2EDTA) were used to collect samples. Aliquots of blood (100 $\mu$ l) obtained from each animal were incubated with $10 \mathrm{ml}$ RPMI-1640 medium with stable glutamine (product code: L0498-100 Biowest, France) containing 5\% fetal bovine serum (FBS, BioWhittaker® reagents, Lonza, Belgium) for $2 \mathrm{~h}$. The following sample groups were allocated: 1) control samples; 2) E407a at a concentration of $10 \mathrm{mg} / \mathrm{ml}$; 3) E407a at a concentration of $50 \mathrm{mg} / \mathrm{ml}$; 4) LPS (L2630-10MG, lipopolysaccharides from Escherichia coli 0111:B4 purified by phenol extraction, Sigma Aldrich, Israel) whose final concentration was $1 \mu \mathrm{g} / \mathrm{ml}$; 5) both E407a $(10 \mathrm{mg} / \mathrm{ml})$ and LPS (1 $\mu \mathrm{g} / \mathrm{ml}) ; 6)$ E407a (50 mg/ml) and LPS (1 $\mu \mathrm{g} / \mathrm{ml}$ ). The study design is available in Figure 1. LPS was added 30 minutes before the end of incubation.

Incubation was followed by the preparation of leukocyte suspensions for further evaluation of the redox state of PBMCs and features of leukocyte cell membranes. Erythrocytes were lysed using BD Pharm Lyse ${ }^{\mathrm{TM}}$ Lysing Buffer (Becton, Dickinson and Company, BD Biosciences, San Jose, CA, USA) in accordance with the standard protocol with a double wash procedure using phosphate-buffered saline (PBS, pH 7.4, $\mathrm{BD}^{\mathrm{TM}}$ CellWash, Becton, Dickinson and Company, BD Biosciences, Poland).

The research was carried out in accordance with the EU Directive 2010/63/EU on the protection of animals used for scientific purposes and the Council of Europe Convention for the Protection of Vertebrate Animals used for Experimental and other Scientific Purposes (ETS123). The Committee of Bioethics (Kharkiv National Medical University, Kharkiv, Ukraine) approved the study design.

\section{Evaluation of Redox Homeostasis Alterations}

To detect ROS production in living leukocytes, the fluorescent probe 2',7'-dichlorodihydrofluorescein diacetate (H2DCFDA) was employed. This ROSsensitive dye is cleaved by intracellular esterases to form 2',7'-dichlorodihydrofluorescein, which is converted into highly fluorescent 2',7'dichlorofluorescein (DCF) whose fluorescence degree reflects the intracellular ROS levels. According to the staining protocol used, leukocytes resuspended in 100 $\mu \mathrm{l}$ PBS were stained with $10 \mu \mathrm{l}$ APC-Cy ${ }^{\mathrm{TM}} 7$ mouse anti-rat CD45 (BD Pharmingen, USA) for 15 minutes for discrimination of leukocytes, $5 \mu l$ 7aminoactinomycin D (7-AAD, BD Pharmingen, USA) for 15 minutes to detect living cells and freshly prepared 5 $\mu \mathrm{M}$ H2DCFDA (Invitrogen ${ }^{\mathrm{TM}}$, USA) working solution in PBS. The fluorescence data were acquired by FACS Canto II flow cytometer (BD Biosciences, USA). DCF was excited by the $488 \mathrm{~nm}$ laser and its fluorescence was detected at $535 \mathrm{~nm}$ (FL1). 7-AAD was excited using the same laser, while emission was measured at $647 \mathrm{~nm}$ (FL3). Apy-Cy7 was excited by the $633 \mathrm{~nm}$ laser and the emitted fluorescence was detected at 760 $\mathrm{nm}$.

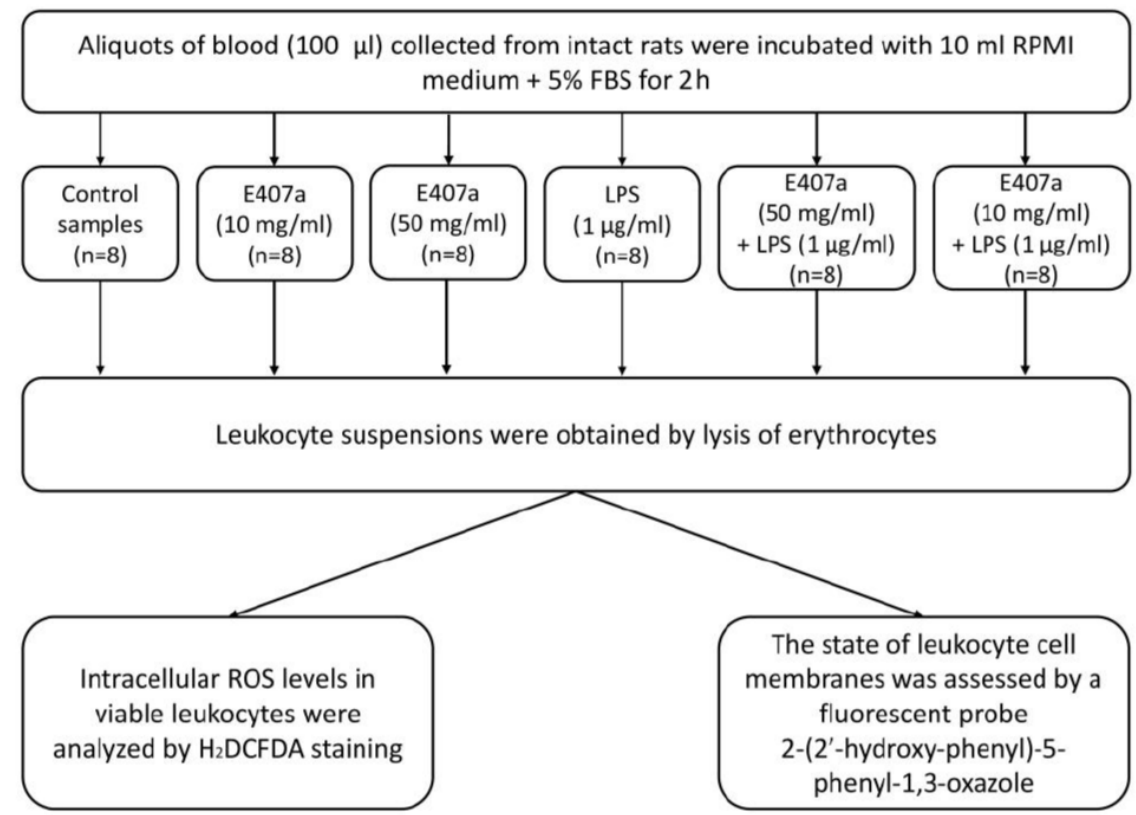

Figure 1: Schematic diagram of experimental design. 

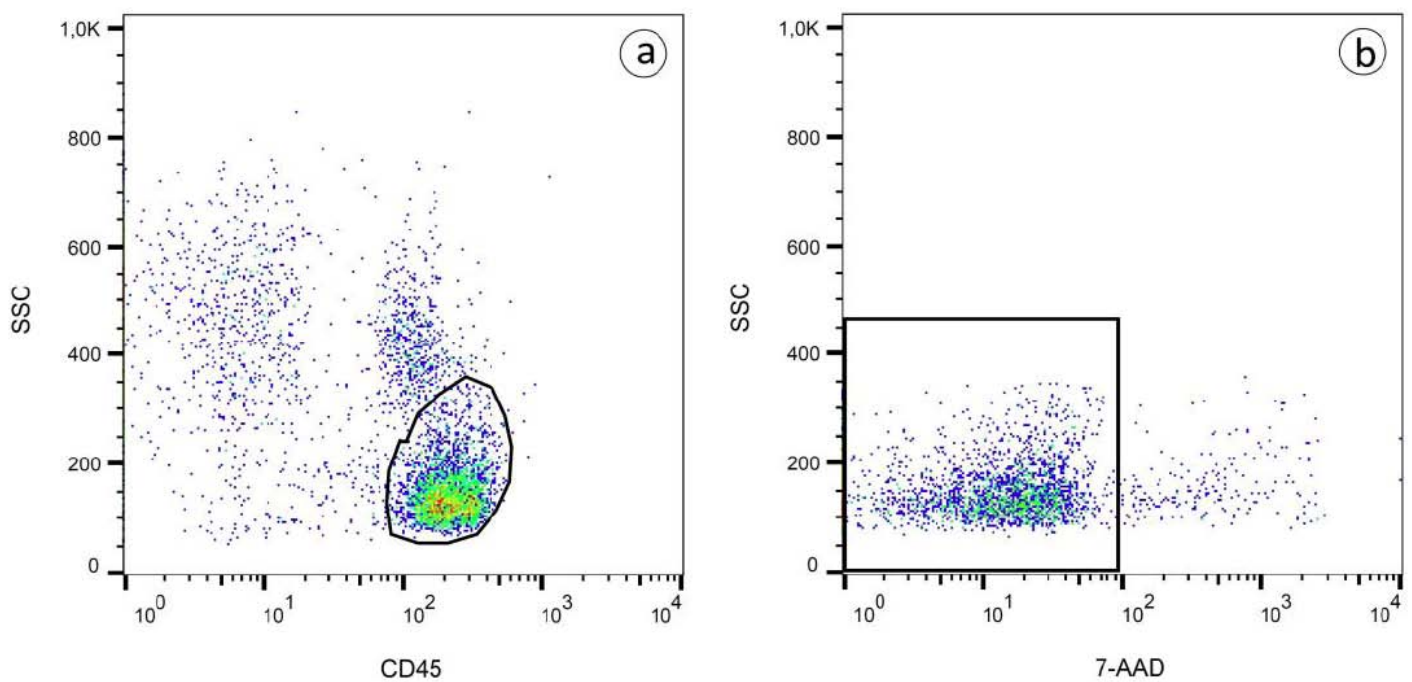

Figure 2: Gating strategy. Firstly, the population of $C D 45^{+}$cells was identified in a FL6 vs. side scatter (SSC) plot (panel a). Secondly, viable CD $45^{+}$cells were selected in a FL3 vs. SSC plot based on 7-aminoactinomycin D (7-AAD) staining (panel b).

Debris was excluded and populations of firstly PBMCs and then viable PBMCs were isolated using the gating strategy available in Figure 2.

\section{Assessment of the State of Cell Membranes in Leukocyte by a Fluorescent Probe}

Cell fluorescent labelling was performed in the following way. To prepare a working solution of probe 2-(2'-hydroxy-phenyl)-5-phenyl-1,3-oxazole, its stock solution in acetonitrile was used. The chemical synthesis of this probe was described earlier [30]. The final probe concentration in leukocyte suspensions was approximately $5 \cdot 10^{-6} \mathrm{~mol} / \mathrm{L}$. This corresponded to the lipid/probe molar ratio of approximately 200:1. Before proceeding to the measurements, the leukocyte suspensions were incubated with the probes at $24{ }^{\circ} \mathrm{C}$ for $60 \mathrm{~min}$. The fluorescence data were acquired using a fluorescence spectrometer "PerkinElmer FL8500" in the range of $340-550 \mathrm{~nm}$, with an increment of $0.1 \mathrm{~nm}$. The emission scan speed was $240 \mathrm{~nm} / \mathrm{min}$. The excitation wavelength was $330 \mathrm{~nm}$. The excitation and emission slits were $5 \mathrm{~nm}$.

Fluorescent probe 010 2-(2'-hydroxy-phenyl)-5phenyl-1,3-oxazole was used in our research due to the fact that the fluorescence indices of this probe are dependent on the polarity and proton-donor ability of its microenvironment [31-34].

The localization of 2-(2'-hydroxy-phenyl)-5-phenyl-1,3oxazole is available in Figure 3 . It is located in the region of glycerol heads of phospholipids (closer to the center of the lipid bilayer), in the area of carbonyl groups and hydrocarbon chains of phospholipid molecules near the region of the carbonyl groups of phospholipids [34].

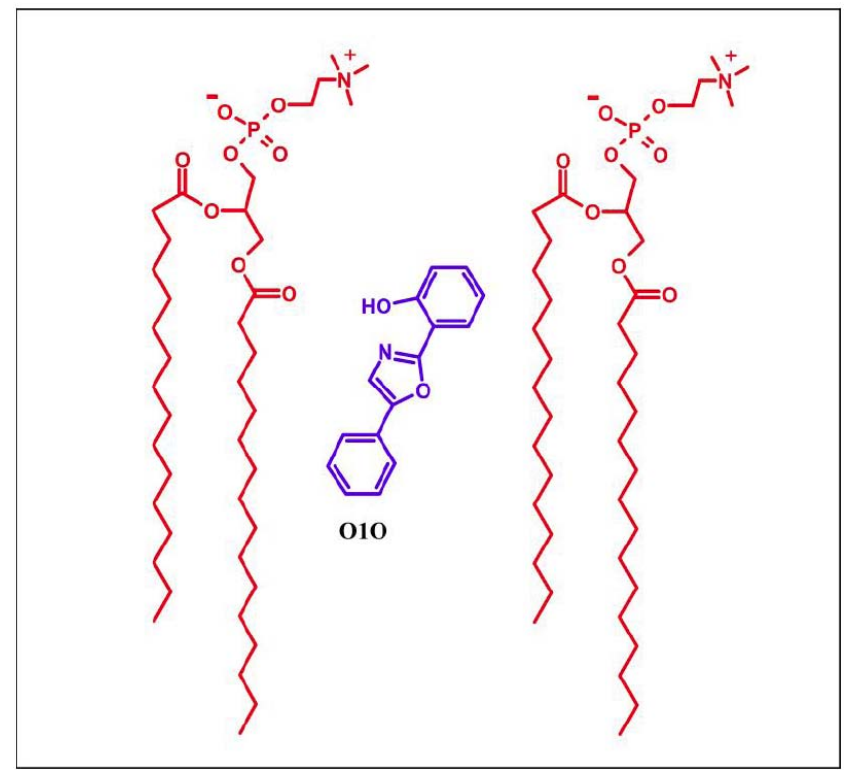

Figure 3: Image that demonstrates the site of fluorescent probe $\mathrm{O} 10$ location in cell membranes. Two molecules of 1,2-dipalmitoyl-phosphatidylcholine located in the outer leaflet of phospholipid bilayer are visualized to show the localization (Adapted from [34]).

When the probe $\mathrm{O} 10$ gets excited, the excited state proton transfer reaction takes place [30-33]. This reaction implies the formation of phototautomer form $\left(T^{*}\right)$, which is fluorescent in significantly longer wavelengths compared with the initial (or so-called "normal") form $\left(\mathrm{N}^{*}\right)$ [31-34].

The presence of two-band fluorescence provides the opportunity to carry out the ratiometric measurement, 

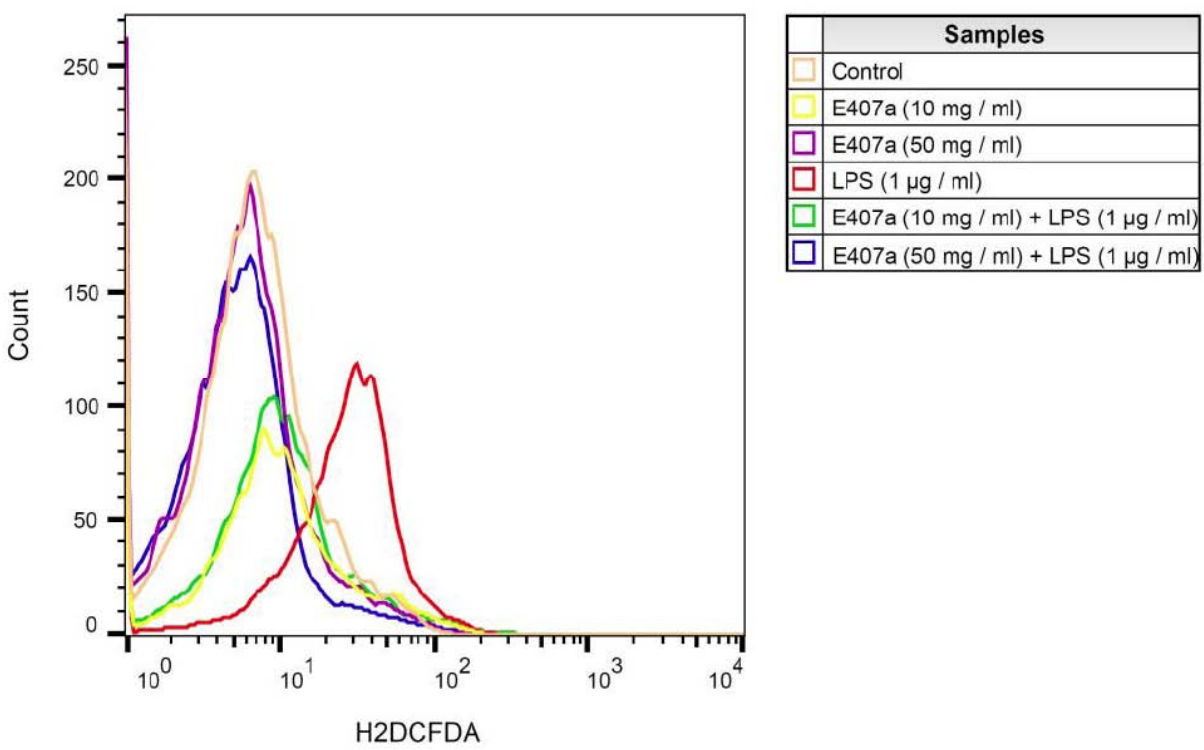

Figure 4: Representative SSC/FL1 histograms that reflect dichlorofluorescein (DCF) fluorescence in peripheral blood mononuclear cells (PBMCs) exposed to semi-refined carrageenan (E407a), lipopolysaccharide (LPS) and their combinations for $2 \mathrm{~h}$.

i.e. to determine the phototautomer form fluorescence intensity-to-the initial form fluorescence intensity ratio $\left(I_{T^{*}} / I_{N^{*}}\right)$. This index can be used to quantitatively characterize the alterations of physical and chemical properties of the probe microenvironment. For example, the $\mathrm{I}_{T^{*}} / \mathrm{I}_{\mathrm{N}^{*}}$ ratio gets reduced in response to the growth of polarity and/or proton-donor ability [3134].

Given that higher hydration of the phospholipid bilayer promotes an increase in the proton-donor ability and polarity $[35,36], 2-(2$-hydroxy-phenyl)-5-phenyl-1,3oxazole indicates the modifications of the hydration of lipid membranes [31]. Since the changes in membrane hydration suggest the changes in the membrane lipid order [37-39], the probe can be used to detect them.

\section{Statistical Analysis}

To test the distribution normality, the Shapiro-Wilk criterion was used. Kruskal-Wallis test followed by post hoc Dunn's test was chosen to compare means of six groups of variables, which were not normally distributed. Data were reported as the median and interquartile range. A value of $P$ below 0.05 was statistically significant. To perform statistical analysis, GraphPad Prism 5.0 software (USA) was used.

\section{RESULTS}

Parameters associated with the redox status of viable PBMCs exposed to E407a, LPS and their combinations are compared in Figures $\mathbf{3}$ and $\mathbf{4}$.
Expectedly, exposure of cells to LPS increased more than 2.1-fold intracellular ROS levels compared with control untreated samples. The samples incubated with semi-refined carrageenan for $2 \mathrm{~h}$ were found to be unaffected in terms of ROS production, evidenced by the absence of statistically significant changes in MFI values of DCF in PBMCs (Figure 5). The effects were not observed even when a higher concentration of the food additive was used. Moreover, the treatment of samples with the mixture of E407a and LPS resulted in no changes in MFI values of DCF compared with the controls. However, a higher concentration of E407a (50 $\mathrm{mg} / \mathrm{ml}$ ) surprisingly reduced the LPS-induced ROS generation suggesting that E407a can partially reduce LPS-induced ROS overproduction (Figure 5).

Outcomes of fluorescence measurements of the spectra of fluorescent probe $\mathrm{O} 10$ embedded in cell membranes of leukocytes incubated with E407a, LPS or their mixtures can be found in Figures 6 and 7 .

A considerable statistically valid approximately $30 \%$ decrease in the fluorescence intensity ratio $\mathrm{I}_{\mathrm{T}^{*}} \mathrm{I}_{\mathrm{N}^{*}}$ $\left(\mathrm{I}_{475} / \mathrm{I}_{370}\right)$ was observed in leukocyte suspensions incubated with LPS (Figures 6 and 7) in comparison with the control samples. Such increase in the $I_{T^{*}} / I_{\mathrm{N}^{*}}$ ratio is indicative of both the increase in polarity and the proton-donor ability of the environment of probe 010 in the leukocyte membranes, suggesting an increase in membrane hydration in the area of the probe location. The increased hydration, in its turn, indicates the decrease in membrane lipid order (Figure 7). 


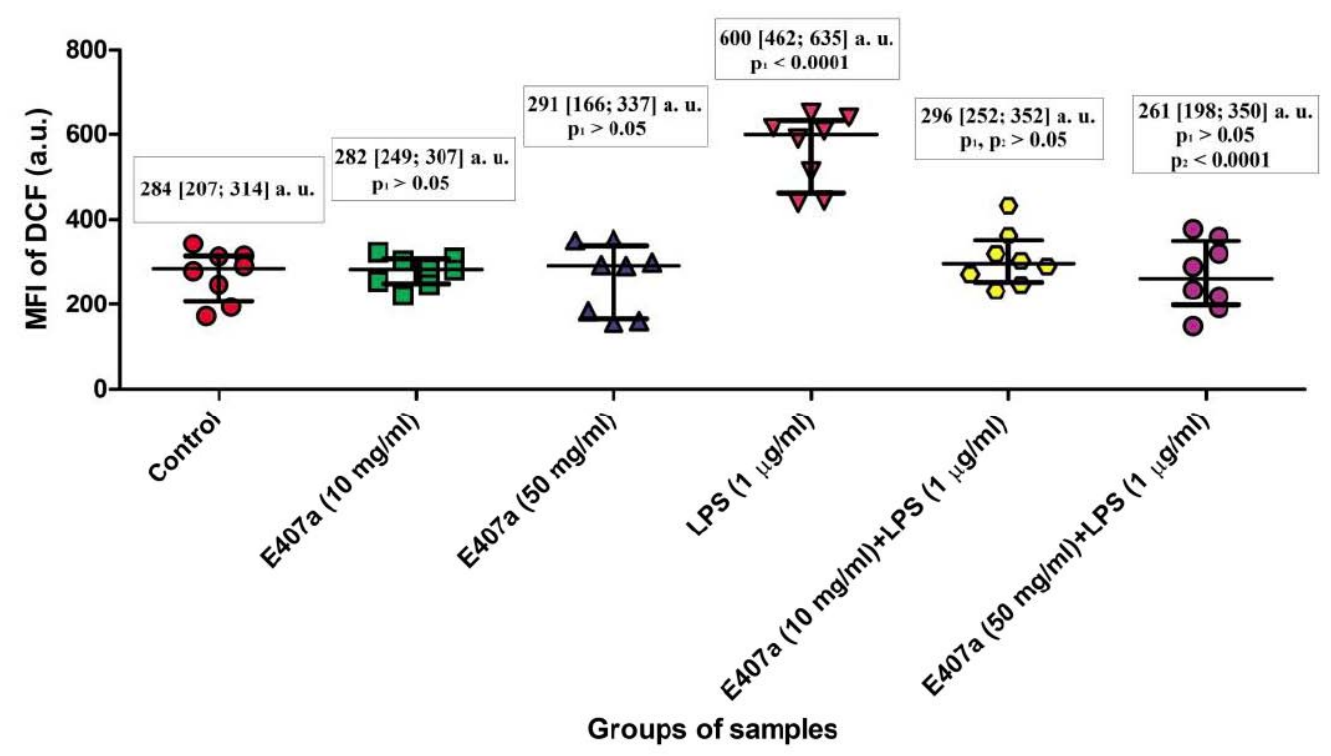

$p_{1}$ indicates the difference with the control group

$\mathrm{p}_{2}$ indicates the difference with the LPS-treated samples

Figure 5: Comparison of mean fluorescence intensities (MFI) of dichlorofluorescein (DCF) in peripheral blood mononuclear cells (PBMCs) exposed to semi-refined carrageenan (E407a), lipopolysaccharide (LPS) and their combinations for $2 \mathrm{~h}$.
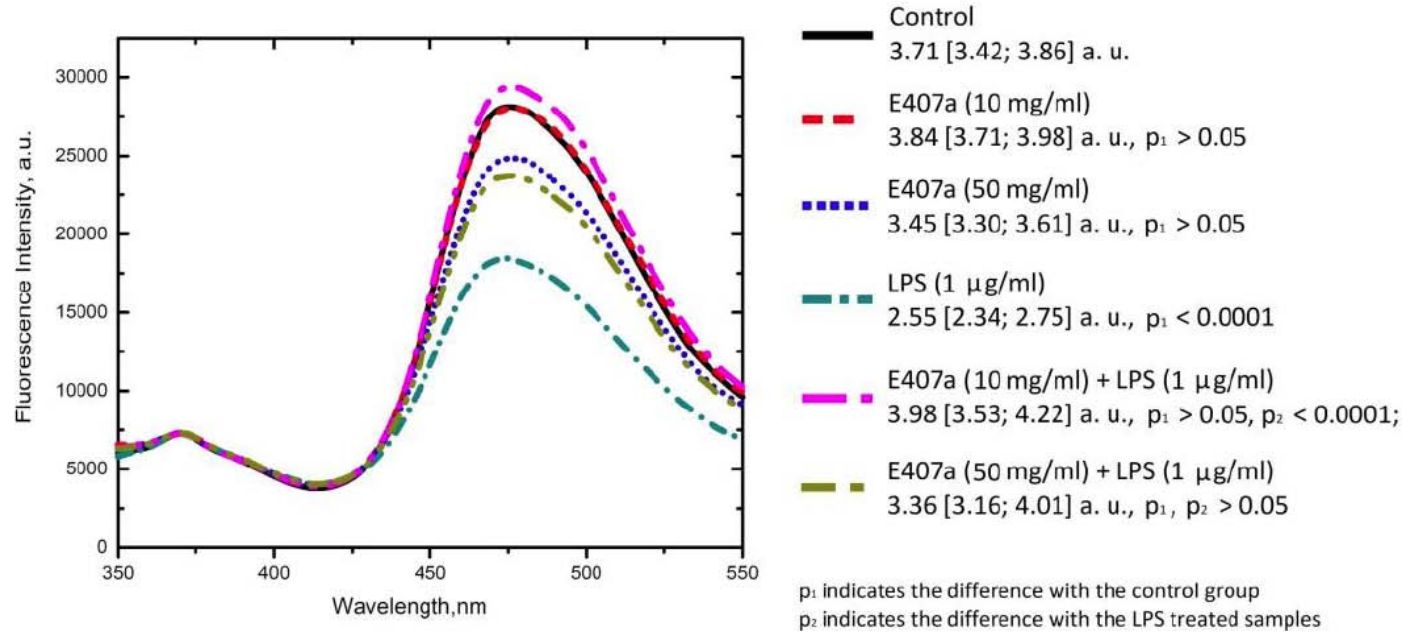

Figure 6: Representative fluorescence spectra of probe 010 in leukocyte suspensions obtained from blood: (a) control samples (black solid line), (b) exposed to $10 \mathrm{mg} / \mathrm{ml} \mathrm{E407a} \mathrm{(red} \mathrm{short} \mathrm{dash} \mathrm{line),} \mathrm{(c)} \mathrm{exposed} \mathrm{to} 50 \mathrm{mg} / \mathrm{ml}$ E407a (blue short dot line), (d) treated with $1 \mu \mathrm{g} / \mathrm{ml}$ lipopolysaccharide (LPS) (dark cyan short dash dot line), (e) exposed to the mixture of $10 \mathrm{mg} / \mathrm{ml} \mathrm{E} 407 \mathrm{a}$ and $1 \mu \mathrm{g} / \mathrm{ml}$ LPS (margenta dash dot line), (f) incubated with the mixture of $50 \mathrm{mg} / \mathrm{ml}$ E407a and $1 \mu \mathrm{g} / \mathrm{ml}$ LPS (dark yellow dash dot dot line). To facilitate the comparison, the spectra were normalized to the fluorescence intensity of the normal form. The averaged values of $\mathrm{I}_{\mathrm{T}^{*}} / \mathrm{I}_{\mathrm{N}^{*}}\left(\mathrm{I}_{475} / \mathrm{I}_{370}\right)$ ratio of probe $\mathrm{O} 10$ are presented for each group of rats.

On the other hand, in comparison with the corresponding spectra for the control samples, no statistically significant changes in the ratio of the fluorescence intensities of the phototautomer and normal forms $\left(I_{T^{*}} / I_{N^{*}}\right.$, i.e. $\left.I_{475} / I_{370}\right)$ of probe 010 were detected for the lipid membranes of leukocytes which are exposed to E407a in both concentrations incubated for $2 \mathrm{~h}$ (Figures 6, 7). It is important to emphasize that in comparison with the control group, no significant changes in the polarity and the proton-donor ability in the membrane area, where probe 010 locates, were observed for the suspension exposed to the mixtures of E407a (50 mg per $\mathrm{ml}$ ) and LPS, evidenced by no statistically significant changes in the ratio of the fluorescence intensities of the probe phototautomer and normal forms (Figure 6). However, the incubation with $10 \mathrm{mg} / \mathrm{ml} \mathrm{E407a}$ and LPS resulted in a statistically significant increase $(\mathrm{p}<0.0001)$ in the $\mathrm{I}_{\mathrm{T}^{*}} / \mathrm{I}_{\mathrm{N}}$ ratio compared with the samples treated exclusively with LPS. 


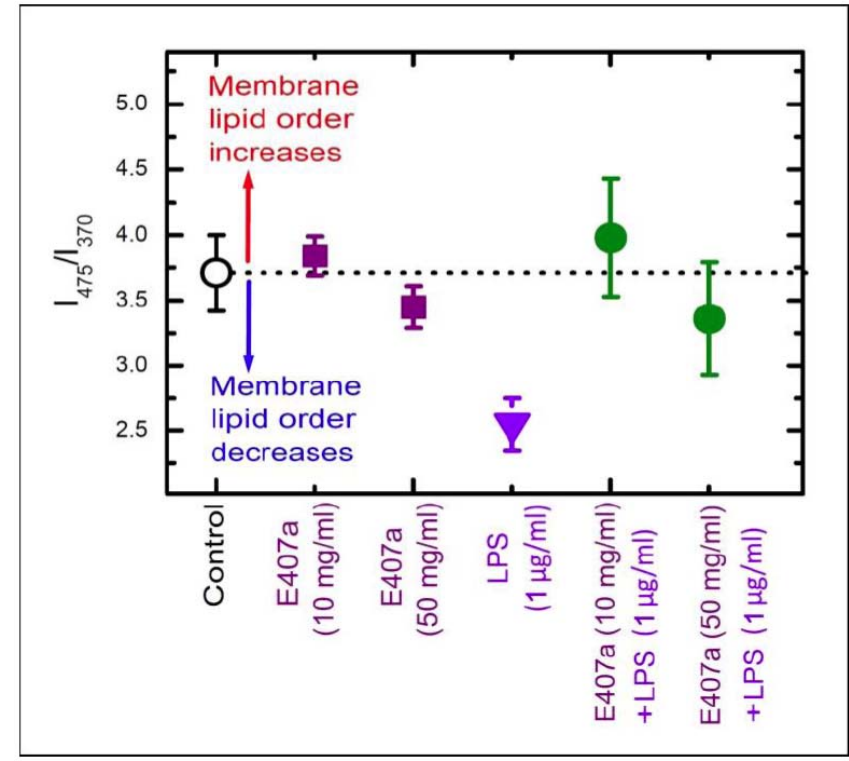

Figure 7: The median fluorescence intensity ratios $\mathrm{I}_{\mathrm{T}^{*}} \mathrm{I}_{\mathrm{N}^{*}}$ $\left(\mathrm{I}_{475} / \mathrm{I}_{370}\right)$ of probe $\mathrm{O} 10$ in leukocytes of rats exposed to: (a) $\mathrm{E} 407 \mathrm{a}$ at the concentrations of $10 \mathrm{mg} / \mathrm{ml}$ and $50 \mathrm{mg} / \mathrm{ml}$ (purple squires), (b) LPS (violet triangle), (c) mixtures of E407a $(10 \mathrm{mg} / \mathrm{ml}$ and $50 \mathrm{mg} / \mathrm{ml}$, respectively) and LPS (filled olive circles), (d) control group of animals (open black circle) are shown to visualize the effects of substances used in this study on the cell membrane lipid order.

\section{DISCUSSION}

Bacterial LPS is a well-described component of the cell wall in Gram-negative bacteria, which acts as a PAMP and ligand for receptors of the innate immune system, especially TLR4 [40, 41]. Downstream effects of TLR4-LPS complex formation in immune cells include the activation of NADPH oxidase with the corresponding overproduction of ROS and overexpression of NF-kBdependent pro-inflammatory cytokines $[42,43]$. It is important to note that LPS is capable of inducing the inflammatory ROS-mediated response in PBMCs [43].

Unsurprisingly, in this study, direct incubation of blood with LPS was found to promote ROS generation in PBMCs and diminish the fluidity of cell membranes in leukocytes, supported by the observed changes in the fluorescence values of fluorescent probe, since the fluidity of phospholipid bilayer decreases in response to free radical-induced peroxidation of polyunsaturated fatty acids, which are essential components of cell membranes responsible for the maintenance of bilayer fluidity [44, 45]. Thus, LPS-mediated changes in the fluidity of cell membranes develop at least partially due to ROS-triggered lipid peroxidation, which causes the reduction of the relative amount of PUFAs in phospholipids. This reduces the lipid order in cell membranes making them more rigid.
In this study, semi-refined carrageenan did not induce ROS generation in leukocytes after incubation for $2 \mathrm{~h}$, even at high concentrations. These data corroborate our earlier findings on the inability of E407a to alter redox homeostasis of rat leukocytes after a short-term incubation [16], but, on the other hand, this contradicts other studies that support the presence of direct prooxidant effects of carrageenans on immune cells in vitro [15]. However, experimental in vivo data provide evidence that carrageenans are known to induce oxidative stress in leukocytes, activate nitric oxide synthesis, cytokine production in macrophages and promote apoptosis of circulating leukocytes [16, 46-49].

Surprisingly, in this study, semi-refined carrageenan was found to partially inhibit LPS-induced ROS generation and LPS-mediated changes in phospholipid bilayers of cell membranes in vitro. This is inconsistent with reports stating that carrageenans stimulate LPSinduced generation of TNF- $\alpha$ in leukocytes without affecting the expression of this cytokine alone in the absence of LPS [50]. However, in vivo studies demonstrate that carrageenan stimulates macrophages even in a more pronounced way compared with LPS [49]. Moreover, experiments on murine models show that kappa-carrageenan magnifies LPS-induced inflammation via the bcl-10-NF-kB pathway [29]. These inconsistencies between our findings and literature data may be explained by the direct interactions of LPS and carrageenans, since carrageenan has been shown to directly alter the morphology and, thus, functional activity of LPS suggesting, on the contrary, the protective and inhibitory role of carrageenans in LPSinduced inflammation [51].

Thus, our results don't exclude the synergistic proinflammatory effects of carrageenans and LPS in vivo. Therefore, future researches should aim at closing the gap in elucidating the crosstalks between the ingested carrageenan, gut microbiome and host immune system. This is especially important for individuals with compromised intestinal barrier integrity and already existing intestinal inflammation.

\section{CONCLUSIONS}

Semi-refined carrageenan stimulated neither ROS overproduction in PBMCs, nor changes in the physicochemical properties of cell membranes in leukocytes directly exposed to this food additive for $2 \mathrm{~h}$. On the contrary, the food additive reduces the LPS-mediated pro-inflammatory effects in leukocytes as a whole and PBMCs in particular. 


\section{CONFLICT OF INTEREST}

Authors declare no conflict of interest.

\section{FUNDING}

The study was performed as a fragment of the research entitled "Biochemical Mechanisms for the Induction of Intestinal Inflammation and the Ways of its Correction (Kharkiv National Medical University, Kharkiv, Ukraine; state registration number 0120U102645).

The study was funded by the National Research Foundation of Ukraine in the framework of the research project №2020.02/0404 entitled "Development of Intelligent Technologies for Assessing the Epidemic Situation to Support Decision-Making within the Population Biosafety Management."

\section{REFERENCES}

[1] Carocho M, Morales P, Ferreira ICFR. Natural food additives: Quo vadis? Trends in Food Science \& Technology 2015; 45(2): 284-295 https://doi.org/10.1016/j.tifs.2015.06.007

David S, Shani Levi C, Fahoum L, et al. Revisiting the carrageenan controversy: do we really understand the digestive fate and safety of carrageenan in our foods? Food Funct 2018; 9(3): 1344-1352. https://doi.org/10.1039/C7FO01721A

Genicot-Joncour S, Poinas A, Richard O, et al. The cyclization of the 3,6-anhydro-galactose ring of iotacarrageenan is catalyzed by two D-galactose-2,6sulfurylases in the red alga Chondrus crispus. Plant Physiol 2009; 151(3): 1609-16. https://doi.org/10.1104/pp.109.144329

[4] McKim JM, Willoughby JA Sr, Blakemore WR, et al. Clarifying the confusion between poligeenan, degraded carrageenan, and carrageenan: A review of the chemistry, nomenclature, and in vivo toxicology by the oral route. Crit Rev Food Sci Nutr 2019; 59(19): 3054-3073 https://doi.org/10.1080/10408398.2018.1481822

[5] Necas J, Bartosikova L. Carrageenan: a review. Veterinarni Medicina 2013; 58: 187-205 https://doi.org/10.17221/6758-VETMED

[6] Tobacman JK, Wallace RB, Zimmerman MB. Consumption of carrageenan and other water-soluble polymers used as food additives and incidence of mammary carcinoma. Med Hypotheses 2001; 56: 589-98. https://doi.org/10.1054/mehy.2000.1208

[7] Borthakur A, Bhattacharyya S, Anbazhagan AN, et al. Prolongation of carrageenan-induced inflammation in human colonic epithelial cells by activation of an NFKB-BCL10 loop. Biochim Biophys Acta 2012; 1822(8): 1300-7. https://doi.org/10.1016/i.bbadis.2012.05.001

[8] Bhattacharyya S, Liu H, Zhang Z, et al. Carrageenaninduced innate immune response is modified by enzymes that hydrolyze distinct galactosidic bonds. J Nutr Biochem 2010; 21(10): 906-13 https://doi.org/10.1016/i.jnutbio.2009.07.002

[9] Bhattacharyya S, Borthakur A, Pant N, et al. Bcl10 mediates LPS-induced activation of NF-KB and IL-8 in human intestinal epithelial cells. American Journal of PhysiologyGastrointestinal and Liver Physiology 2007; 293(2): 429-437. https://doi.org/10.1152/ajpgi.00149.2007

[10] Borthakur A, Bhattacharyya S, Dudeja PK, et al. Carrageenan induces interleukin-8 production through distinct Bcl10 pathway in normal human colonic epithelial cells. American Journal of Physiology-Gastrointestinal and Liver Physiology 2007; 292(3): 829-838. https://doi.org/10.1152/ajpgi.00380.2006

[11] Lopes AH, Silva RL, Fonseca MD, et al. Molecular basis of carrageenan-induced cytokines production in macrophages. Cell Commun Signal 2020 Sep 7; 18(1): 141 https://doi.org/10.1186/s12964-020-00621-x

Myers MJ, Deaver CM, Lewandowski AJ. Molecular mechanism of action responsible for carrageenan-induced inflammatory response. Mol Immunol 2019; 109: 38-42. https://doi.org/10.1016/j.molimm.2019.02.020

[13] Bhattacharyya S, Gill R, Chen ML, et al. Toll-like receptor 4 mediates induction of the Bcl10-NFkappaB-interleukin-8 inflammatory pathway by carrageenan in human intestinal epithelial cells. J Biol Chem 2008 Apr 18; 283(16): 10550-8. https://doi.org/10.1074/jbc.M708833200

[14] Korneev KV, Atretkhany KN, Drutskaya MS, et al. TLRsignaling and proinflammatory cytokines as drivers of tumorigenesis. Cytokine 2017 Jan; 89: 127-135. https://doi.org/10.1016/j.cyto.2016.01.021

[15] Sokolova EV, Karetin Y, Davydova VN, et al. Carrageenans effect on neutrophils alone and in combination with LPS in vitro. J Biomed Mater Res A 2016; 104(7): 1603-9. https://doi.org/10.1002/jbm.a.35693

[16] Tkachenko AS, Kot YG, Kapustnik VA, et al. Semi-refined carrageenan promotes reactive oxygen species (ROS) generation in leukocytes of rats upon oral exposure but not in vitro. Wien Med Wochenschr 2021; 171(3-4): 68-78. https://doi.org/10.1007/s10354-020-00786-7

[17] Tkachenko AS, Onishchenko Al, Gorbach TV, et al. O-6methylguanine-DNA methyltransferase (MGMT) overexpression in small intestinal mucosa in experimental carrageenan-induced enteritis. Malay. J. Biochem. Mol. Biol 2018,21 (3); 77-80.

[18] Tkachenko AS, Marakushyn DI, Rezunenko YK, et al. A study of erythrocyte membranes in carrageenan-induced gastroenterocolitis by method of fluorescent probes. HVM Bioflux 2018; 10(2): 37-41.

[19] Tkachenko A, Marakushyn D, Kalashnyk I, et al. A study of enterocyte membranes during activation of apoptotic processes in chronic carrageenan-induced gastroenterocolitis. Med Glas (Zenica) 2018; 15(2): 87-92.

[20] Gubina-Vakyulyk GI, Gorbach TV, Tkachenko AS, et al. Damage and regeneration of small intestinal enterocytes under the influence of carrageenan induces chronic enteritis. Comparative Clinical Pathology, 2015; 24(6): 1473-1477. https://doi.org/10.1007/s00580-015-2102-3

[21] Bhattacharyya S, Xue L, Devkota S, et al. Carrageenaninduced colonic inflammation is reduced in Bcl10 null mice and increased in $\mathrm{IL}-10$-deficient mice. Mediators of Inflammation 2013; 2013: 13. https://doi.org/10.1155/2013/397642

[22] Weiner ML, McKim JM. Comment on "Revisiting the carrageenan controversy: do we really understand the digestive fate and safety of carrageenan in our foods?" by $S$. David, C. S. Levi, L. Fahoum, Y. Ungar, E. G. Meyron-Holtz, A. Shpigelman and U. Lesmes, Food Funct., 2018, 9, 13441352. Food Funct 2019; 10(3): 1760-1762. https://doi.org/10.1039/C8FO01282B

[23] McKim JM, Willoughby JA Sr, Blakemore WR, et al. Clarifying the confusion between poligeenan, degraded carrageenan, and carrageenan: A review of the chemistry, 
nomenclature, and in vivo toxicology by the oral route. Crit Rev Food Sci Nutr 2018: 1-20.

https://doi.org/10.1080/10408398.2018.1481822

[24] McKim JM Jr, Baas H, Rice GP, et al. Effects of carrageenan on cell permeability, cytotoxicity, and cytokine gene expression in human intestinal and hepatic cell lines. Food Chem Toxicol 2016; 96: 1-10.

https://doi.org/10.1016/j.fct.2016.07.006

[25] Weiner ML. Food additive carrageenan: Part II: A critical review of carrageenan in vivo safety studies. Critical Reviews in Toxicology 2014; 44: 244-69.

https://doi.org/10.3109/10408444.2013.861798

[26] Tkachenko AS, Onishchenko Al, Lesovoy VN, et al. Common food additive E407a affects BCL-2 expression in lymphocytes in vitro. Studia Univ. VG, SSV,2019; 29(4): 16976.

[27] McKim JM Jr, Wilga PC, Pregenzer JF, et al. The common food additive carrageenan is not a ligand for Toll-LikeReceptor 4 (TLR4) in an HEK293-TLR4 reporter cell-line model. Food Chem Toxicol 2015; 78: 153-8. https://doi.org/10.1016/j.fct.2015.01.003

[28] Shang Q, Sun W, Shan X, et al. Carrageenan-induced colitis is associated with decreased population of anti-inflammatory bacterium, Akkermansia muciniphila, in the gut microbiota of C57BL/6J mice. Toxicol Lett 2017; 279: 87-95. https://doi.org/10.1016/j.toxlet.2017.07.904

[29] Wu W, Zhen Z, Niu T, et al. $\mathrm{k}$-Carrageenan enhances lipopolysaccharide-induced interleukin-8 secretion by stimulating the Bcl10-NF-KB Pathway in HT-29 cells and aggravates $C$. freundii-induced inflammation in mice. Mediators Inflamm 2017; 2017: 8634865. https://doi.org/10.1155/2017/8634865

[30] Doroshenko AO, Posokhov EA, Shershukov VM, et al. Spectral and luminescence properties of derivatives of 2-aryl[9,10]-phenanthroxazole. Chem. Heterocycl. Comp 1995; 31(4): 492-499. https://doi.org/10.1007/BF01177024

[31] Posokhov YO, Kyrychenko A, Korniyenko Y. Derivatives of 2,5-diaryl-1,3-oxazole and 2,5-diaryl-1,3,4-oxadiazole as environment-sensitive fluorescent probes for studies of biological membranes. Reviews in Fluorescence 2017 (editor C.D. Geddes), Springer Nature Switzerland AG, Chapter 9; 2018. pp 199-230.

https://doi.org/10.1007/978-3-030-01569-5 9

[32] Doroshenko AO, Posokhov EA, Verezubova AA, et al. Radiationless deactivation of excited phototautomer form and molecular structure of ESIPT- compounds. Photochem Photobiol Sci 2002; 1: 92-9.

https://doi.org/10.1039/b107255m

[33] Doroshenko AO, Posokhov EA, Shershukov VM, et al. Intramolecular proton-transfer reaction in an excited state in a series of ortho-hydroxy derivatives of 2,5-diaryloxazole. High Energy Chemistry 1997; 31(6): 388-394.

[34] Posokhov $Y$, Kyrychenko A. Location of fluorescent probes (2-hydroxy derivatives of 2,5-diaryl-1,3-oxazole) in lipid membrane studied by fluorescence spectroscopy and molecular dynamics simulation. Biophysical Chemistry 2018; 235: 9-18.

https://doi.org/10.1016/j.bpc.2018.01.005

[35] Kurad D, Jeschke G, Marsh D. Lipid membrane polarity profiles by high-field EPR. Biophys. J 2003; 85: 1025-1033. https://doi.org/10.1016/S0006-3495(03)74541-X

[36] Bartucci R, Guzzi R, Marsh D, et al. Intramembrane polarity by electron spin echo spectroscopy of labeled lipids. Biophys. J 2003; 84: 1025-1030.

https://doi.org/10.1016/S0006-3495(03)74918-2
[37] Ho C, Slater SJ, Stubbs CD. Hydration and order in lipid bilayers. Biochemistry 1995; 34: 6188- 6195.

https://doi.org/10.1021/bi00018a023

[38] Binder H, Gawrisch K. Effect of unsaturated lipid chains on dimensions, molecular order and hydration of membranes. J. Phys. Chem., B 2001; 105: 12378- 12390. https://doi.org/10.1021/jp010118h

[39] Noethig-Laslo V, Šentjurc M. Transmembrane polarity profile of lipid membranes. Advances in Planar Lipid Bilayers and Liposomes 2006, Academic Press, Elsevier, Vol. 5, Chapter 13 , pp. 365-415. https://doi.org/10.1016/S1554-4516(06)05013-7

[40] Kuzmich NN, Sivak KV, Chubarev VN, et al. TLR4 Signaling Pathway Modulators as Potential Therapeutics in Inflammation and Sepsis. Vaccines (Basel) 2017; 5(4): 34. https://doi.org/10.3390/vaccines5040034

[41] Murdock JL, Núñez G. TLR4: The winding road to the discovery of the LPS Receptor. J Immunol 2016; 197(7): 2561-2.

https://doi.org/10.4049/jimmunol.1601400

[42] Wan J, Shan Y, Fan Y, et al. NF-kB inhibition attenuates LPS-induced TLR4 activation in monocyte cells. Mol Med Rep 2016; 14(5): 4505-4510. https://doi.org/10.3892/mmr.2016.5825

[43] Ngkelo A, Meja K, Yeadon $M$, et al. LPS induced inflammatory responses in human peripheral blood mononuclear cells is mediated through NOX4 and Gia dependent PI-3kinase signalling. J Inflamm (Lond) 2012; 9(1): 1. https://doi.org/10.1186/1476-9255-9-1

[44] Harayama T, Shimizu T. Roles of polyunsaturated fatty acids, from mediators to membranes. J Lipid Res 2020; 61(8): $1150-1160$

https://doi.org/10.1194/jlr.R120000800

[45] Catalá Á. Lipid peroxidation modifies the assembly of biological membranes "The Lipid Whisker Model". Front Physiol 2015; 5: 520 https://doi.org/10.3389/fphys.2014.00520

[46] Tkachenko A, Pogozhykh D, Onishchenko A, et al. Gadolinium Orthovanadate GdVO4: Eu3+ Nanoparticles Ameliorate Carrageenan-Induced Intestinal Inflammation. J Pharm Nutr Sci 2021; 11(1): 40-48. https://doi.org/10.29169/1927-5951.2021.11.06

[47] Tkachenko A, Onishchenko A. Oral Intake of Semi-refined Carrageenan by Rats Affects Apoptosis of Lymphocytes. Annals of Colorectal Research, 2020; 8(4): 170-174.

[48] Tkachenko A. Reactive oxygen species (ROS) generation by lymphocytes in rats treated with a common food additive E407a. J Clin Med Kaz 2020; 1(55): 22-26. https://doi.org/10.23950/1812-2892-JCMK-00744

[49] Nacife VP, Soeiro Mde N, Gomes RN, et al. Morphologica and biochemical characterization of macrophages activated by carrageenan and lipopolysaccharide in vivo. Cell Struct Funct 2004; 29(2): 27-34. https://doi.org/10.1247/csf.29.27

[50] Ogata M, Matsui T, Kita T, et al. Carrageenan primes leukocytes to enhance lipopolysaccharide-induced tumor necrosis factor alpha production. Infect Immun 1999; 67(7): 3284-9.

https://doi.org/10.1128/IAI.67.7.3284-3289.1999

[51] Yermak IM, Volod'ko AV, Khasina El, et al. Inhibitory Effects of Carrageenans on Endotoxin-Induced Inflammation. Mar Drugs 2020; 18(5): 248. https://doi.org/10.3390/md18050248 